Original article

Paediatrics Today 2014;10(2):95-103

DOI $10.5457 / \mathrm{p} 2005-114.95$

\title{
BODY MASS INDEX IN CEREBRAL PALSY PATIENTS WITH VARIOUS MOTOR SEVERITIES
}

\author{
Azra DELALIĆ, Nedima KAPIDŽIĆ-BAŠIĆ, Alma GLINAC
}

Department of Physical Medicine and Rehabilitation, University Clinical Centre Tuzla, Tuzla, Bosnia and Herzegovina

Corresponding author:

Azra Delalić

Department of Physical Medicine

and Rehabilitation

University Clinical Centre Tuzla

75000 Tuzla

Bosnia and Herzegovina azradelalic@hotmail.com

Tel.: + $38735303-135$

Fax.: + $38735303-148$

Received: March 13, 2014

Accepted: May 12, 2014

Copyright (C) 2014 by University Clinical Centre Tuzla. E-mail for permission to publish: paediatricstoday@ukctuzla.ba

\begin{abstract}
Objective - To determine the nutritional status of children and adolescents with cerebral palsy (CP) in relation to the degree of functional disability. Patients and methods - This cross sectional study analyzed the nutritional status of 73 children and adolescents of both sexes suffering from CP, with an average age expressed as a median of 9.6 years (range 2.6 to 19.4). Evaluation of nutritional status in patients with $\mathrm{CP}$ was done on the basis of Body Mass Index (BMI). The degree of functional disability was assessed on the basis of the Gross Motor Function Classification System (GMFCS levels I-V). BMI percentiles were expressed by sex and chronological age, based on national standards in 2000 Centers for Disease Control and Prevention Growth Charts for the United States. Results - Of the total number of participants, $21.9 \%$ were underweight (BMI $<5^{\text {th }}$ percentile), $11 \%$ were overweight (BMI from $85^{\text {th }}$ to $95^{\text {th }}$ percentile) and $9.6 \%$ were obese $\left(\mathrm{BMI}>95^{\text {th }}\right.$ percentile). Most malnourished participants had a clinical form of quadriplegia, whereas and overweight and obese had diplegia. There is a significant negative correlation between BMI percentile and the degree of functional disability according to the GMFCS $(\mathrm{p}=0.0001)$. Immobile participants (GMFCS IV-V) showed a high prevalence of malnutrition (39.4\%) compared to the self-mobile participants (GMFCS I-II, 4.3\%). Obesity was present in $17.3 \%$ selfmoving participants (GMFCS I-II) and in $17.6 \%$ mobile participants with mobile device support (GMFCS III), and none of the immobile children were obese. Conclusion - About $40 \%$ of children and adolescents with CP have nutrition problems, where half of them are malnourished and the other half are over-nourished. Immobile children and those with quadriplegia have a higher risk for malnutrition, whereas mobile children and those with diplegia have a higher risk for over-nutritional status.
\end{abstract}

Key words: Cerebral palsy - Malnourished - Obesity - Functional disability.

\section{Introduction}

Cerebral palsy (CP) is the most common cause of disability in childhood. It is described as a clinical entity that indicates a group of variable motor disorders caused by a non-progressive disorder or brain damage in the early developmental period, often accompanied by sensory disorders, perception, cognition, communication, behavior, epilepsy and secondary musculoskeletal problems 
(1). Odding et al. (2) followed the epidemiological characteristics of CP from 1965 to 2004 , citing an increase in the prevalence of $\mathrm{CP}$, with greater representation in poorer socio-economic conditions. The most common form is the spastic form, and besides motor difficulties, $25 \%-80 \%$ of patients with CP have additional difficulties. A large portion of these children have some degree of cognitive impairment, especially children with epileptic seizures. Epilepsy was reported in $20 \%-40 \%$, speech disorders in $80 \%$, visual disorders in $75 \%$, gastrointestinal disturbances and feeding difficulties in 50\%, slower growth in $25 \%$ and the problems of malnutrition or overweight in $50 \%$ cases. According to research by McManus et al. (3), $29.5 \%$ children with CP have intellectual difficulties, with an IQ $<50$, and $30.3 \%$ are unable to move, even with support.

The life expectancy of people with perinatal brain damage and consequent CP may be similar to that in the general population, or much shorter. A child who has a severe form of CP diagnosed at the age of two years has about a $40 \%$ chance of living to the age of twenty, in contrast to children with milder forms of CP where the chances are $99 \%$. Cerebral palsy, respiratory disorders, epilepsy and congenital malformations are the most common causes of premature death in children (4). As the life span of the person with $\mathrm{CP}$ is being extended, world-wide activities are being conducted to prevent secondary problems for individuals with disabilities, which would compromise their general health. Slow growth and malnutrition are important secondary health problems that affect the general health and well-being of the persons with CP and their families.

Malnutrition may weaken the respiratory muscles and lead to the cardio respiratory problems, exacerbate gastrointestinal disorders, such as gastro oesophageal reflux, reduce immunity and thus increase sensitiv- ity to infections, slow cognitive development and reduce the interest of the child to the environment (5). Most children with CP have oral muscle dysfunction and feeding difficulties at an early age, which can interfere with the growth and nutritional status. Well timed rehabilitation and feeding interventions can significantly improve the nutritional status and quality of life of children with CP (6).

As well as malnutrition, children with CP have a risk of over-nutrition and obesity. People with disabilities, regardless of gender, race, nationality or age, have a significantly higher prevalence of overweight and obesity compared to people without disabilities (7). Growth in children with CP is associated with their general state of health and participation in society. Slow and insufficient growth often leads to deterioration of the general health of the child, thus increasing the number of health services needed, as well as the number of absences from school or other activities in the family or outside of it (8).

The aim of the research was to determine the nutritional status of children and adolescents with CP in relation to the degree of functional disability.

\section{Patients and methods}

The nutritional status of 73 children and adolescents with CP was analysed using a cross sectional study. The survey was conducted from June 2013 to January 2014 at the Department of Physical Medicine and Rehabilitation, University Clinical Centre Tuzla. Functional status was assessed by the Gross Motor Function Classification System or GMFCS (9), with five levels of disability which vary according to chronological maturity, classified for: up to 2 years, from 2 years to 4 years, from 4 to 6 years and from 6 to 12 years of age. The same criteria were applied for subjects older than 12 years as for children 6-12 years old. The first and second 
level of disability (GMFCS I and II) include children who walk independently, with minimal restrictions outside the home and for longer distances. The third level (GMFCS III) includes children who use a mobility aid (crutches, walkers) with significant restrictions on movement outside the home and over longer distances. The fourth level (GMFCS IV) are children who use wheelchairs to move around, while the fifth level (GMFCS V) includes immobile children, whose movement is very limited, or who move with the aid of a wheelchair because of their inability to control their head and body when sitting. On the basis of clinical examination, medical documentation and data taken from the parents, we evaluated the clinical form of cerebral palsy and the additional problems. These additional problems were regarding epileptic seizures, the ability to understand spoken or written linguistic information, the possibility of verbal or non-verbal expression, feeding difficulties in terms of the inability to chew and to take in solid food, hypersalivation and the need for feeding in supine positions. In all of the patients their body height and weight were measured and their date of birth and gender were recorded. Height was measured as the maximum distance from the feet to the highest point on the head, in standing or recumbent positions depending on the participants' ability to stand. Heels, knees, buttocks and back were in contact with the wall or on the bed, at best with the help of the assistants. Weight was measured in light clothes, on a digital scale individually or in the arms of another person. On the basis of these data Body Mass Index (BMI) was automatically calculated using the criteria established on the basis of national standards in 2000 of the Centres for Disease Control and Prevention Growth Charts for the United States or CDC standards (10). The degree of nutritional status was assessed on the basis of the CDC norms within four categories: BMI $<5^{\text {th }}$ percentile indicates underfed subjects, a BMI between the $5^{\text {th }}$ and $85^{\text {th }}$ percentile of normal nutritional status subjects, BMI from the $95^{\text {th }}$ to $85^{\text {th }}$ percentile indicates the excessive nutritional status of subjects or risk for obesity and BMI $>95^{\text {th }}$ percentile obesity.

\section{Ethical aspects}

Before the examination by the first author of this study, every parent of a child with $\mathrm{CP}$ was acquainted with the purpose of the review and was asked to sign a pre-filled form of consent to participate in the study. Written informed consent was obtained from participating mothers for their child to take part in the study.

\section{Statistical analysis}

Statistical analysis was performed by the statistical software package "Arcus Biomedical Quickstat". All variables were tested for normal distribution using the KolmogorofSmirnov test. Median and interquartile range were calculated from the descriptive statistical parameters. These results are presented in absolute and relative numbers and in tables, columns and diagrams in addition to textual comment. The frequencies of qualitative variables were compared using the hi-square test. Testing the relationship between the variables was done using the Pearson correlation. The required alpha level of significance that was used in these analyses was set at $\mathrm{p}<0.05$.

\section{Results}

Our sample represented 73 children and adolescents with $\mathrm{CP}$, with average age expressed as median 9.6 years (range 2.6 to 19.4). The demographic data of the participants is summarized in Table 1.

In total, $31(42.5 \%)$ of the subjects had a deviation from normal body weight according 
Table 1 Characteristics of children with cerebral palsy $(n=73)$

\begin{tabular}{lr}
\hline Characteristics & $\mathrm{n}(\%)$ \\
\hline Gender & \\
\hline Female & $33(45.2)$ \\
Male & $40(54.8)$ \\
\hline Age & \\
\hline$<10$ years & $38(52.1)$ \\
$>10$ years & $35(47.9)$ \\
\hline Clinic form of CP & \\
\hline Spastic quadriplegia & $18(24.7)$ \\
Spastic diplegia & $37(50.7)$ \\
Spastic hemiplegia & $10(13.7)$ \\
Dyskinetic & $3(4.1)$ \\
Ataxic & $5(6.8)$ \\
\hline Gross Motor Function Classification System & \\
\hline Level I & $14(19.2)$ \\
Level II & $9(12.3)$ \\
Level III & $17(23.3)$ \\
Level IV & $12(16.4)$ \\
Level V & $21(28.8)$ \\
\hline Feeding & \\
\hline Feeds by mouth without problems & $60(82.2)$ \\
\hline Feeds by mouth but with difficulty & $13(17.8)$ \\
\hline Speech difficulties & $56(76.7)$ \\
\hline No & $17(23.3)$ \\
\hline Yes & \\
\hline Cognitive difficulties & \\
\hline No & \\
\hline Yes & \\
\hline No & \\
\hline & \\
\hline Yes & \\
\hline
\end{tabular}

to the CDC criteria, among them 16 (21.9\%) were undernourished, 8 (11\%) were overnourished and 7 (9.6\%) were obese (Fig. 1).

$34.3 \%$ patients older than 10 years and $10.5 \%$ younger patients were found to suffer from malnutrition, which was statistically significant $(\chi 2=6.335 ; \mathrm{p}=0.04)$. A larger number of male participants (25\%) were malnourished compared to female participants (18.2\%), but without statistical significance $(\chi 2=0.495 ; \mathrm{p}=0.78)$. Additional difficulties were recorded in underweight and normal weight participants. There was a statistically significantly higher number of underweight participants with cognitive and speech difficulties $(56.2 \%)$ compared to $19 \%$ normal weight participants $(\chi 2=14.707 ; \mathrm{p}=0.02)$, as well as participants with feeding difficulty, with $43.7 \%$ in underweight participants compared to $14.2 \%$ of those with normal weight $(\chi 2=10.962 ; \mathrm{p}=0.01)$, which was statistically significant. Overweight and obese participants are represented almost equally in both sexes and in relation to the age of the participants. Also in this group there were no participants with additional disabilities.

Malnutrition is present in all clinical forms of CP. Half of the malnourished participants had a clinical form of quadriplegia. All of the overnourished and most of the obese subjects had a diplegic form of CP (Table 2).

In relation to functional capacity, the highest number of the undernourished (39.4\%) were in the group of immobile children and adolescents (GMFCS IV-V), followed by $11.7 \%$ in participants moving with an aid (GMFCS III) and the least (4.3\%) were self-moving participants (GMFCS I-II).

The highest number of over-nourished children and adolescents were in the group moving with an aid (23.5\%), followed by self-moving $(13.1 \%)$, while only one participant from the immobile group fulfilled the criteria of fixed CDC standards for this category of nutritional status. Obesity was present in $17.6 \%$ of those moving with an aid and $17.4 \%$ self- moving participants, and none of the participants in the immobile group was obese (Table 3 ).

Table 4 shows the anthropometric characteristics of the participants. The median percentile of height and weight decreased with the increasing degree of disability, as well as BMI, where there was a statistically significant negative correlation $(r=-0.43 ; \mathrm{p}=0.0001)$. 


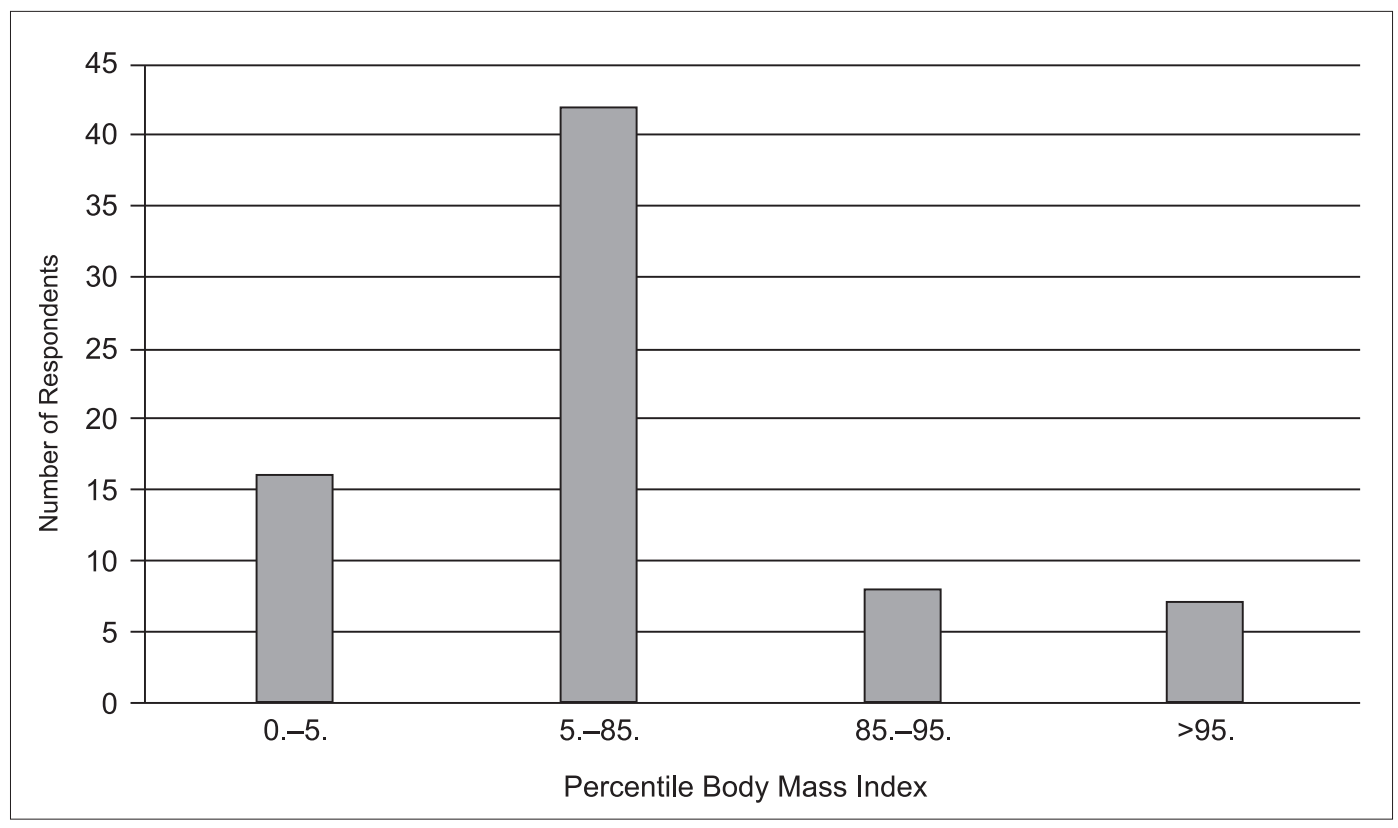

Fig. 1 Distribution of percentile Body Mass Index in participants with cerebral palsy.

\section{Table 2 Percentile of body mass index in participants with cerebral palsy compared to the clinical form}

\begin{tabular}{llllll}
\hline \multirow{2}{*}{$\begin{array}{l}\text { Body mass index } \\
\left(\mathrm{kg} / \mathrm{m}^{2} \text {; percentile) }\right.\end{array}$} & \multicolumn{5}{l}{ Clinical type of cerebral palsy } \\
\cline { 2 - 6 } & $\begin{array}{l}\text { Spastic } \\
\text { quadriplegia }(\mathrm{n}=18)\end{array}$ & $\begin{array}{l}\text { Spastic } \\
\text { diplegia }(\mathrm{n}=37)\end{array}$ & $\begin{array}{l}\text { Spastic } \\
\text { hemiplegia }(\mathrm{n}=10)\end{array}$ & $\begin{array}{l}\text { Dyskinetic } \\
\text { form }(\mathrm{n}=3)\end{array}$ & $\begin{array}{l}\text { Ataxic form } \\
(\mathrm{n}=5)\end{array}$ \\
\cline { 2 - 6 } & $\mathrm{n}(\%)$ & $5(13.5)$ & $1(10.0)$ & $1(33.3)$ & $1(20.0)$ \\
\hline $5^{\text {th }}$ & $8(44.4)$ & $19(51.4)$ & $7(70.0)$ & $2(66.7)$ & $4(80.0)$ \\
$5^{\text {th }}-85^{\text {th }}$ & $10(55.6)$ & $8(21.6)$ & - & - & - \\
$85^{\text {th }}-95^{\text {th }}$ & - & $5(13.5)$ & $2(20.0)$ & - & - \\
$>95^{\text {th }}$ & - & & & & \\
\hline
\end{tabular}

Table 3 Percentile of body mass index in participants with cerebral palsy in relation to mobility

\begin{tabular}{llll}
\hline \multirow{2}{*}{$\begin{array}{l}\text { Centile of body } \\
\text { mass index }\left(\mathrm{kg} / \mathrm{m}^{2}\right)\end{array}$} & $\begin{array}{l}\text { Mobility } \\
\text { Independently moveable } \\
\text { (GMFCS I-II; } \mathrm{n}=23)\end{array}$ & $\begin{array}{l}\text { Moving with an aid } \\
\text { (GMFCS III; } \mathrm{n}=17)\end{array}$ & $\begin{array}{l}\text { Immobile } \\
\text { (GMFCS IV-V; } \mathrm{n}=33)\end{array}$ \\
\cline { 2 - 4 } & $\mathrm{n}(\%)$ & $2(11.8)$ & $13(39.4)$ \\
\hline$<5^{\text {th }}$ & $1(4.3)$ & $8(47.1)$ & $19(57.6)$ \\
$5^{\text {th }}-85^{\text {th }}$ & $15(65.2)$ & $4(23.5)$ & $1(3.0)$ \\
$85^{\text {th }}-95^{\text {th }}$ & $3(13.1)$ & $3(17.6)$ & - \\
$>95^{\text {th }}$ & $4(17.4)$ & & \\
\hline
\end{tabular}


Table 4 Anthropometric characteristics in participants with cerebral palsy in relation to mobility

\begin{tabular}{llll}
\hline \multirow{2}{*}{ Mobility } & \multicolumn{4}{l}{ Anthropometric indicators (Centiles) } \\
\cline { 2 - 4 } & \multicolumn{4}{l}{ Height $(\mathrm{cm})$} & Weight $(\mathrm{kg})$ & BMI $\left(\mathrm{kg} / \mathrm{m}^{2}\right)$ \\
\cline { 2 - 4 } & Median (IQR) & & \\
\hline Independently moveable (GMFCS I-II; $\mathrm{n}=23)$ & $55(10-81)$ & $62(9-94)$ & $56(15-92)$ \\
Moving with an aid (GMFCS III; $\mathrm{n}=17)$ & $9(1.5-29)$ & $33(2.5-82.5)$ & $68(18.5-92.5)$ \\
Immobile (GMFCS IV-V; $\mathrm{n}=33)$ & $2(0-9.5)$ & $1(0-12)$ & $9(1-43.5)$ \\
The total number of participants $(\mathrm{n}=73)$ & $9(1-41.5)$ & $12(1-70)$ & $39(6-72.5)$ \\
\hline
\end{tabular}

BMI=Body mass index; IQR=Interquartile range.

\section{Discussion}

The high prevalence of obesity in mobile children with $\mathrm{CP}$ and diplegia corresponds to the results of other authors $(11,12)$. The prevalence of obesity has increased in the general paediatric population by more than $10 \%$ in the United States (13). A similar increase in the prevalence of obesity in the last decade has also been found in children with CP in a range from $7.7 \%$ to $16.5 \%$ (14). The prevalence of obesity in adolescents with physical and cognitive disabilities is significantly higher compared to adolescents without disabilities (15). Excessive obesity in mobile children with $\mathrm{CP}$ may be explained by the clinical characteristics of diplegic or hemiplegic forms of CP in which we do not find difficulties in terms of swallowing, cognition, speech, etc. However, although the food intake of these children is satisfactory, their physical activity is insufficient, they move slowly at short distances so the ratio between energy intake and energy spent is disproportionate, which then leads to excessive nutrition. The aerobic capacity of children and adolescents with CP, classified as GMFCS level I and II, was significantly lower in correlation with children with normal development (16). During normal daily activities, children with spastic diplegia were significantly less active than their healthy peers, as evidenced by the significantly smaller proportion of energy consumed daily and the rate of metabolism during sleep (17).
Malnutrition is also common in the population of children with CP, especially in the immobile group. Half the malnourished participants have quadriplegia, and more than three-quarters are immobile, as stated in this research and by other authors (11). There is a risk of malnutrition in mobile children with $\mathrm{CP}$, substantially lower BMI in quadriplegia compared to diplegia and hemiplegia, and in GMFCS III in relation to the GMFCS levels I and II (18). Approximately $30 \%$ of the participants with diplegia and $6 \%$ with hemiplegia were malnourished, which is consistent with the results of other authors who state that approximately $30 \%$ of children with a clinical picture of diplegia and hemiplegia were malnourished (12).

In our study, the largest number of malnourished children and adolescents are immobile, in contrast to epidemiological studies of healthy populations, where insufficient physical activity is cited as one of the important factors of excessive nutrition and obesity. An important factor in the malnutrition of disabled children with CP is their insufficient intake of nutritious foods. The reasons for malnutrition in these children, in addition to motor problems, are additional difficulties which are especially emphasized in the most severe form of CP. In their research, Gangil et al. (19) cite the existence of oral dysfunction in all patients with CP, particularly in children with spastic quadriplegia, hypotonia and epileptic attacks. Other authors in their 
studies cite difficulty swallowing in 99\% of children with CP GMFCS levels IV and V, of which $76 \%$ have difficulty to a moderate to severe degree, and $15 \%$ to a very severe degree (20). A multicentre study in the United States and Canada indicated that the severity of feeding dysfunction is strongly associated with indicators of poor health and nutritional status in children with CP. Body weight and height were significantly lower in relation to the clinical picture of $\mathrm{CP}$, but the subjects with a nasogastric tube were taller and had more subcutaneous adipose tissue in relation to children with similar motor impairments who were fed orally. Even children with mild motor dysfunction had less body fat compared to those without difficulty feeding (21). How malnutrition affects the nutritional status of children with severe forms of CP, due to difficulty swallowing or feeding, has been shown in a series of studies related to application of nasogastric tubes or gastrostomy feeding in order to improve the population. How much insufficient nutrition, due to difficulties swallowing or feeding affects the nutritional status of children with severe forms of CP has been proven by a large amount of research related to the use of nasogastric tubes or gastrostomy in order to improve the nutrition of this population. .Body height and weight were significantly lower in correlation to the values of the general paediatric population in children with a higher degree of disability, including children with gastrostomy, who are taller and $2-5 \mathrm{~kg}$ heavier than those without gastrostomy (22, 23). Besides swallowing, in children with $\mathrm{CP}$, especially those who are malnourished, we found various gastrointestinal disorders, the most common of which are gastro esophageal reflux and constipation (24).

Another factor in the malnutrition of disabled children with CP is muscle spasticity. Children with CP have higher energy consumption and lower aerobic capacity due to increased muscle tone, muscle spasms and involuntary movements (25). Research, showing the role of spasticity in malnutrition, used baclofen pumps in children and adolescents with hypertension of central origin in order to reduce spasticity. In addition to reducing spasticity, a statistically significant difference was found in weight gain a year before and one year after installation of a baclofenic pump (26).

In addition to optimal nutrition, in some children with CP we found slower growth and development, indicating the existence of non-nutritive factors. Anthropometric measurements in children with hemiplegia showed normal nutritional status and body height for chronological age, but there was a reduction of all anthropometric parameters on the hemiparetic side of the body (27). A great deal of research has been done in children with spastic or mixed forms of CP with moderate to severe functional disability, in whom skeletal maturation has been delayed by more than two years (28). Children with CP grow more slowly than children who do not have a chronic disease, and slower growth was recorded in boys, younger children, and malnourished and disabled children (29).

\section{Limitations of the research and future directions}

There are several limitations of this study. First, the study was conducted on a relatively small sample. Second, assessment of nutritional status was performed using anthropometric measurements and BMI. Body weight and BMI are not the most suitable methods for measuring nutritional status in children with severe neurological disabilities (30). Third, children should undergo laboratory testing in order to address protein, minerals, vitamins, etc. deficits, and in the obese glucose and lipids as indicators of metabolic syndrome. This country, like most other 
countries, does not have standard guidelines for measuring anthropometric parameters and uses European or American standards that were created for the population of children living in those areas. Anthropometric measurements should be undertaken in a large number of children in our country, in order to design our own corresponding table or a standard curve that could be used as a guideline for the assessment of growth and nutritional status.

\section{Conclusion}

About $40 \%$ of children and adolescents with $\mathrm{CP}$ have nutritional problems, half of them being malnourished and the other half over nourished. There is a higher risk for malnutrition in immobile and quadriplegic children, and excessive nutritional status in children with mobile and diplegic forms of CP.

Authors' contributions: Conception and design: AD; Acquisition, analysis and interpretation of data: $\mathrm{AD}$; AG; Drafting the article AD; Revising it critically for important intellectual content: AD. NKB, AG.

Conflict of interest: The authors declare that they have no conflict of interest.

\section{References}

1. Bax M, Goldstein M, Rosenbaum P, Leviton A, Paneth N, Dan B, et al. Proposed definition and classification of cerebral palsy. Dev Med \& Child Neurol. 2005;47:571-6.

2. Odding E, Roebroeck ME, Stam HJ. The epidemiology of cerebral palsy: incidence, impairments and risk factors. Disabil Rehabil. 2006;28(4):18391.

3. McManus V, Guillem P, Surman G, Cans C. SCPE work, standardisation and definition.an overview of the actives of SCPE: a collaboration of European CP registers. Zhongguo Dang Dai Er Ke Za Zhi. 2006;8(4):261-5.

4. Hutton JL.Cerebral palsy life expectancy. Clin Perinatal. 2006;33(2):545-55.

5. Kuperminc MN, Stevenson RD. Growth and Nutrition Disorders in children with cerebral palsy. Dev Disabil Res Rev. 2008;14(2):137-46.
6. Hou M, Fu P, Zhao JH, Lan K, Zhang H, Zhonghua Er, et al. Oral motor dysfunction, feeding problems and nutritional status in children with cerebral palsy. 2004;42(10):765-8.

7. Rimmer JH, Wang E. Obesity prevalence among a group of Chicago residents with disabilities. Arch Phys Med Rehabil. 2005;86(7):1461-4.

8. Stevenson RD, Conaway M, Chumlea WC, Rosenbaum P, Fung EB, Henderson RC, et al. Growth and health in children with moderate-to-severe cerebral palsy. Pediatrics. 2006;118(3):1010-18

9. Palisano R, Rosenbaum P, Walter S, Russel D, Wood E, Galuppi B. Development and reliability of a system to classify gross motor function in children with cerebral plasy. Dev Med \& Child Neurol. 1997;39(4):214-23.

10. Kuszmarski RJ, Ogden CL, Guo SS, GrummerStrawn LM, Flegal KM, Mei Z, et al. 2000 CDC growth charts for the United States: methods and development. Vital Health Stat 11. 2002;(246):1190.

11. Hurvitz EA, Green LB, Hornyak JE, Khurana SR, Koch LG. Body mass index measures in children with cerebral palsy related to gross motor function classification: a clinic-based study. Am J Phys Med rehabil. 2008;87:395-403.

12. Stallings VA, Chamey EB, Davies JC, Cronk CE. Nutritional status and growth of children with diplegic or hemiplegic cerebral palsy. Dev Med Child Neurol. 1993;35(11):997-1006.

13. Ogden CL, Flegal KM, Carroll MD, Johnson CL. Prevalence and trends in overweight among US children and adolescents, 1999-2000. JAMA. 2002;288(14):1728-32.

14. Rogozinski BM, Davids JR, Davis RB, Christopher LM, Anderson JP, Jameson GG, et al. Prevalence of obesity in ambulatory children with cerebral palsy. J Bone Joint Surg Am. 2007;89(11):2421-6

15. Rimmer JH, Yamaki K, Davis BM, Wang E, Vogel LC. Obesity and overweight prevalence among adolescents with disabilities. Prev Chronic Dis. 2011;8(2):A41.

16. Verschuren O, Takken T. Aerobic capacity in children and adolescents with cerebral palsy. Res Dev Disabil. 2010;31(6):1352-7.

17. Van den Berg-Emons HJ, Saris WH, de Barbanson DC, Westerterp KR, Huson A, van Baak MA. Daily physical activity of schoolchildren with spastic diplegia and of healthy control subjects. J Pediatr. 1995;127(4):578-84. 
18. Feeley BT, Gollapudi K, Otsuka NY. Body mass index in ambulatory cerebral palsy patients. J Pediatr Orthop. 2007;B16(3):165-9.

19. Gangil A, Patwari AK, Aneja S, Ahuja B, Anand VK. Feeding problems in children with cerebral palsy. Indian Pediatr. 2001;38(8):839-46.

20. Calis EA, Veugelers R, Sheppard JJ, Tibboel D, Evenhuis HM, Penning C. Dysphagia in children with severe generalized cerebral palsy and intellectual disability. Dev Med Child Neurol. 2008;50(8):625-30.

21. Fung EB, Samson-Fang L, Stallings VA, Conaway M, Liptak G, Henderson RC, et al. Feeding dysfunction is associated with poor growth and health status in children with cerebral palsy. J Am Diet Assoc. 2002;102(3):361-73.

22. Day SM, Strauss DJ, Vachon PJ, Rosenbloom L, Shavelle RM, Wu YW. Growth patterns in a population of children and adolescents with cerebral palsy. Dev Med Child Neurol. 2007;49(3):167-71.

23. Shapiro BK, Green P, Krick J, Allen D, Capute AJ. Growth of severely impaired children: neurological versus nutritional factors. Dev Med Child Neurol. 1986;28(6):729-33.

24. Campanozzi A, Capano G, Miele E, Romano A, Scuccimarra G, Del Giudice E, et al. Impact of malnutrition on gastrointestinal disorders and gross motor abilities in children with cerebral palsy. Brain Dev. 2007;29(1):25.

25. Izadi M, Nazem F, Hazavehei M. The effect of sub-maximal exercise-rehabilitation program on cardio-respiratory endurance indexes and oxygen pulse in patients with spastic cerebral. Journal of Research in medical Science. 2006;11(2):93-100.

26. McCoy AA, Fox MA, Schaubel DE, Ayyangar RN. Weight gain in children with hypertonia of cerebral origin receiving intrathecal baclofen therapy. Arch Phys Med Rehabil. 2006; 87(11):1503-6.

27. Stevenson RD, Roberts CD, Vogtle L. The effects of non-nutritional factors on growth in cerebral palsy. Dev Med Child Neurol. 1995;37(2):124-30.

28. Henderson RC, Gilbert SR, Clement ME, Abbas A, Worley G, Stevenson RD. Altered skeletal maturation in moderate to severe cerebral palsy. Dev med Child Neurol. 2005; 47(4):229-36.

29. Samson-Fang L, Stevenson RD. Linear growth velocity in children with cerebral palsy. Dev Med Child Neurol.1998;40(1):689-92.

30. Riley A, Vadeboncoeur Ch. Nutritional differences in neurologically impaired children. Paediatr Child Health. 2012;17(10). 